Artigo original

Hegemonia - Revista Eletrônica de Relações Internacionais do Centro Universitário Unieuro

ISSN: $1809-1261$

UNIEURO, Brasília, número 14, 2014, pp. 88-106.

Recebido em: $21 / 7 / 2014$

Avaliado em:14/8/2014

Aprovado em: 18/9/2014

\title{
A Abordagem Interagência dos Sistemas Proteger e de Monitoramento das Fronteiras Terrestres (SISFRON)
}

Deywisson Ronaldo Oliveira de Souza ${ }^{1}$ e

Stephanie Queiroz Garcia²

Resumo: Abordamos as operações interagências como políticas com estratégias cooperativas na agenda de defesa nacional e mostramos como o Sistema Proteger desenvolve ações especificas para promover a defesa das EETer e da população em grandes eventos. Analisamos a implementação do SISFRON e sua importância para o processo de monitoramento e fiscalização das fronteiras brasileiras

Palavras-Chave: Defesa Nacional; Projetos Estratégicos; PROTEGER; SISFRON.

Abstract: We discuss interagency operations policies as cooperative strategies actions in the national defense agenda and we show how Sistema Proteger develops specific actions to promote the defense of the vital and strategic structures and of the population at big events. We analyze the implementation of SISFRON and Its importance to the process of monitoring and enforcement of the Brazilian borders. Key-Words: National Defense; Strategic Projects; PROTEGER; SISFRON.

\section{Introdução}

1 Mestrando no Programa de Pós-Graduação em Ciência Política da Universidade Federal de Pernambuco (UFPE) e bolsista do Programa Pró-Estratégia da Secretaria de Assuntos Estratégicos (SAE) e CAPES.

2 Doutoranda e Mestra pelo Programa de Pós-Graduação em Ciência Política da UFPE e bolsista FACEPE. 
Artigo original

Hegemonia - Revista Eletrônica de Relações Internacionais do Centro Universitário Unieuro

ISSN: $1809-1261$

UNIEURO, Brasília, número 14, 2014, pp. 88-106.

Em meio ao debate que se levanta sobre as capacidades de defesa do país e frente a sua atuação cada vez mais proeminente nas relações internacionais, a cooperação interagência surge como desafio para as políticas públicas de defesa nacional. Dada a complexidade dos problemas que habitam a agenda de defesa e as suas múltiplas estruturas de causalidade (RAZA, 2012), há quase sempre um grande número de atores com competências similares ou concorrentes para tratar os mesmos temas.

A elaboração de estratégias de ação mais eficientes passa necessariamente pela harmonização dos interesses divergentes existentes nas várias instâncias governamentais que atuam direta ou indiretamente na arena da política a ser enfrentada. Ao saber que as operações interagências são estratégias conjuntas por meio das quais diversas instâncias com escopo de ação e corpos burocráticos diferentes propõem procedimentos compartilhadas para solucionar problemas de arenas hibridas, os questionamentos acerca das soluções e condutas para se amenizar os problemas passaram a ser recorrentes.

O Exército Brasileiro recentemente lançou seis Projetos Estratégicos (PEE) que visam capacitar operacionalmente e tecnologicamente o país em razão das novas exigências e face a demandas nacionais (EXERCITO, 2013). Entre esses projetos está o Sistema Integrado de Proteção das Estruturas Estratégicas Terrestres, o Proteger. Seu objetivo é a promoção de estratégias e ações de proteção das estruturas estratégicas terrestres (EETer), tais como hidroelétricas, gasodutos, redes de abastecimento de água, etc., e da população em ocasiões de grandes eventos. 
Artigo original

Hegemonia - Revista Eletrônica de Relações Internacionais do Centro Universitário Unieuro

ISSN: $1809-1261$

UNIEURO, Brasília, número 14, 2014, pp. 88-106.

No mesmo sentido, percebendo a importância das fronteiras para o projeto brasileiro de defesa, tem-se o projeto complementar ao Proteger, cujo espectro de atuação reside no monitoramento da faixa transfronteiriça por meio do Sistema de Monitoramento das Fronteiras Terrestres (SISFRON). O projeto SISFRON objetiva essencialmente fortalecer a presença do Estado na região de fronteira e incrementar a capacidade de monitoramento de áreas chaves para Defesa Nacional.

O grande desafio do Exército como órgão gerenciador desses programas vai ser elaborar projetos conjuntos com outros órgãos e permitir a construção de visões integradas para tratar dos temas a que se propõem. Para enfrentar esse desafio certamente esses projetos devem passar por etapas que vão da identificação dos problemas a serem enfrentados, passando pela harmonização das culturas burocráticas dos diversos órgãos ligados ao problema até a concretização de estratégias cooperativas em ações especificas para atingir tais problemas.

A despeito do escopo deste paper está fundamentado na atuação do Exército Brasileiro dentro do contexto do Sistema Proteger e do SISFRON, a compreensão da cooperação interagência que perpassa todo o processo tornou-se elemento fundamental para que fosse possível a análise da questão, seja no que se refere ao esforço inicial de integração entre as instituições envolvidas, seja nos desafios a serem enfrentados por este modelo de ação.

Esse trabalho aborda então as operações interagências como políticas com estratégias cooperativas na agenda de defesa nacional, e mostra como o Sistema Proteger pretende por meio de estratégias de cooperação interagência desenvolver ações especificas para promover a defesa das EETer e da população em grandes eventos. No final do trabalho mostramos como a criação da Secretaria Extraordinária de 
Artigo original

Hegemonia - Revista Eletrônica de Relações Internacionais do Centro Universitário Unieuro

ISSN: $1809-1261$

UNIEURO, Brasília, número 14, 2014, pp. 88-106.

Segurança para Grandes Eventos (SESGE) consegue passar por todas as etapas de uma política com caráter interagência e criar um output, uma resposta que interfere no problema presente na agenda da política de defesa. Assim como a implementação do SISFRON pode evidenciar aspectos importantes no que se refere ao processo de monitoramento e fiscalização das vias transfronteiriças através de uma coordenação interagência.

\section{Definindo Operações Interagências}

o termo interagência não é da linguagem comum dos brasileiros, nem mesmo é tão comum entre acadêmicos e policy makers. Sua popularização no mundo é recente, e se intensificou, sobretudo depois da década de 1980, quando passou a ser mais utilizada nos Estados Unidos e Reino Unido. Em se tratando de Brasil raramente ela era utilizada, e o próprio termo agência, como hoje se conhece, um órgão governamental dotado de funções e um plano estratégico de ação, apenas foi formalmente instaurado em 1998, por meio da lei 9.649 (RAZA, 2012, p. 15). Dessa maneira a palavra interagência, e a sua consequente expressão "cooperação interagência", são ainda mais recentes.

Se faz importante salientar que a relação entre as agências no âmbito da gestão pública brasileira sempre ocorreu em certa medida, através de interações simples, desarticuladas e por vezes despropositais, que se constituem através da troca de pareceres, informações, efetivos, entre outros, a fim de resolver questões cujo alcance não seria possível sem a atuação coordenada. A cooperação interagência que tratamos neste trabalho relaciona-se diretamente com o projeto de institucionalização dessas 


\section{Artigo original}

Hegemonia - Revista Eletrônica de Relações Internacionais do Centro Universitário Unieuro

ISSN: $1809-1261$

UNIEURO, Brasília, número 14, 2014, pp. 88-106.

trocas e articulações entre atores buscam agir para um mesmo fim, qual seja a proteção das estruturas estratégicas no caso do Sistema Proteger..

A palavra interagência fornece dois significados, um abstrato, mais ligado a mecanismos e instrumentos para afirmar transparência de ações, não corrupção, status de políticas públicas mais planejadas (RAZA, 2012 p.10). Certamente uma concepção mais atrelada ao discurso. E outro significado prático, onde esses discursos e pretensões avançam até decisões concretas de cooperação. A emergência de uma coordenação interagência justifica-se pela necessidade da formação de um agrupamento de atores (agências) a fim de alcançarem objetivos comuns, buscando fundamentalmente a proteção de bens públicos. No entanto, tal articulação coletiva somente torna-se possível e factível quando tais objetivos não possam ser alcançados individualmente, por um único ator ou instituição. Paul Warmington (et al, 2004) esclarece que a ação interagência acontece quando mais de uma instituição trabalham juntas, sob a orientação de um plano formal, onde seja possível a atuação tanto em nível operacional como em nível estratégico.

No mesmo sentido Eugene Bardach (1998, p.8 apud RAZA, 2012, p.14) entende a ação interagência como a atividade integrada de duas ou mais agências, intencionadas a incrementar determinados valores públicos através de trabalho conjunto, em vez dos esforços individualizados de cada uma delas. Uma outra importante definição do que consistem as operações interagências foi fornecida por Salvador Raza (2012), que as entende como sendo ferramentas para harmonizar culturas burocráticas e esforços divergentes no intuito de construir objetivos compartilhados a serem alcançados em arenas de problemas complexos. E partindo desse princípio de que a interação entre diversas instâncias está direcionada para a 
Artigo original

Hegemonia - Revista Eletrônica de Relações Internacionais do Centro Universitário Unieuro

ISSN: $1809-1261$

UNIEURO, Brasília, número 14, 2014, pp. 88-106.

solução compartilhada de um problema ou para responder a alguma demanda na agenda de políticas públicas, visualizamos a cooperação interagência como uma ação ou intenção compartilhada entre instâncias governamentais e da sociedade civil, para responder a demandas gerenciais de um campo hibrido da agenda de políticas públicas. Essas intenções podem se homogeneizarem e se transformarem, através de decisões conjuntas, em ações políticas concretas.

Podemos entender a colaboração interagência por meio de uma dinâmica de decisões sucessivas e simultâneas, onde: 1) primeiramente o problema na agenda da política pública é identificado. E dada a complexidade dos problemas que tem múltiplas estruturas de causalidade, há quase sempre um grande número de atores com competências similares ou concorrentes para tratar do tema (RAZA, 2012); 2) isso faz com que os tomadores de decisão decidam colaborar por meio de relações institucionais interagentes; 3) depois disso um processo de harmonização das estratégias, onde as partes envolvidas apresentam as suas plataformas de ação, procuram convergir suas culturas burocráticas e visões divergentes. É exatamente nesse momento em que as partes tentam eliminar as competências e estruturas concorrentes que possam atravancar o processo, o que favorece os consensos; 4) esses consensos são visíveis nas políticas e estratégias colaborativas; 4) que criam ações concretas, o output do processo, para responder aos problemas inicialmente identificados (ver figura 1). 
Artigo original

Hegemonia - Revista Eletrônica de Relações Internacionais do Centro Universitário Unieuro

ISSN: $1809-1261$

UNIEURO, Brasília, número 14, 2014, pp. 88-106.

Figura 1 - Fases da colaboração interagência

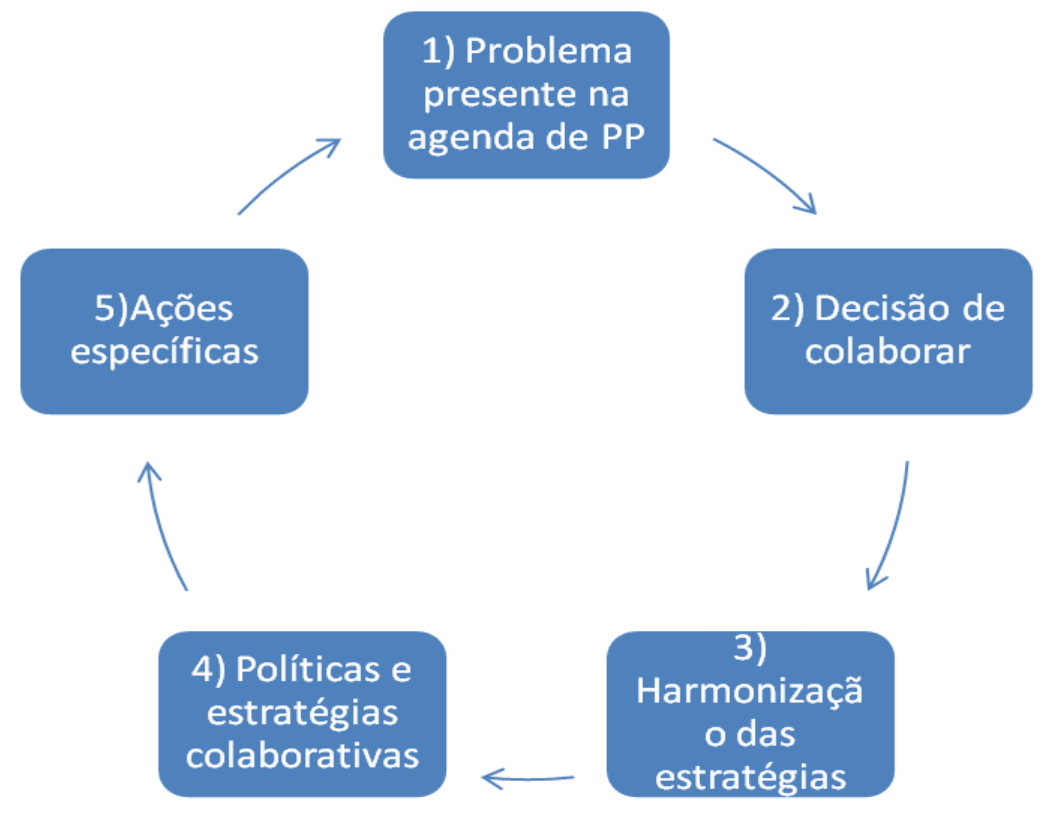

Elaboração Própria.

Frente à adoção de estratégias de gerenciamento compartilhado de problemas, o que deve ser analisado é o seu impacto na gestão pública. Nesse sentido Raza aduz que essas estratégias funcionam como um elemento fomentador e estabilizador de políticas públicas, permitindo o fluxo de ações que produzem resultados (2012, p. 30).

No contexto de aplicação de políticas públicas para a área da defesa no Brasil, é importante ainda denotar o trabalho das Forças Armadas e sua fundamental contribuição para o processo. Admitindo a relevância do tema para a realidade hodierna, o Ministério da Defesa, por meio do Comando do Estado-Maior do Exército, lançou no ano de 2013, um Manual de Campanha de Operações em Ambiente Interagência. $O$ referido documento disponibiliza instruções pormenorizadas a respeito 
Artigo original

Hegemonia - Revista Eletrônica de Relações Internacionais do Centro Universitário Unieuro

ISSN: $1809-1261$

UNIEURO, Brasília, número 14, 2014, pp. 88-106.

da atuação do Exército nessas iniciativas, buscando uniformizar a atuação das Forças Armadas nesse contexto.

Neste fulcro, é oportuno então apresentar também a definição do que seria a cooperação interagência para as Forças Armadas, assim descritas no Manual supracitado. Assim, tal cooperação pode ser compreendida pela interação entre as Forças Armadas com outras agências com a finalidade de conciliar interesses e coordenar esforços para consecução de objetivos ou propósitos convergentes, que atendam ao bem comum, evitando a duplicidade de ações, dispersão de recursos e a divergência de soluções com eficiência, eficácia, efetividade e menores custos. (MINISTÉRIO DA DEFESA, p.1-2, 2013)

Sabendo que as operações interagências são estratégias conjuntas por meio das quais diversas instâncias com escopo de ação e corpo burocráticos diferentes propõem ações compartilhadas para solucionar problemas de arenas hibridas, como o Sistema Proteger se insere nesse contexto? O que lhe confere seu caráter de ação interagência? O que é o SISFRON? Que instituição é a responsável pele o desenvolvimento do projeto? Esses vão ser os questionamentos que vão guiar as próximas seções desse trabalho.

\section{O Sistema PROTEGER}

Para responder a esses questionamentos não podemos tirar de mente que as estratégias de cooperação interagência se inserem em um campo hibrido onde as características marcantes dos problemas a serem atingidos ou evitados são suas estruturas múltiplas de causalidade. 
Artigo original

Hegemonia - Revista Eletrônica de Relações Internacionais do Centro Universitário Unieuro

ISSN: $1809-1261$

UNIEURO, Brasília, número 14, 2014, pp. 88-106.

O Sistema Integrado de Proteção das Estruturas Estratégicas Terrestres (Proteger) é um dos 6 recentes PEE, ações indutoras da transformação do Exército, que visam capacitar operacionalmente e tecnologicamente o país em razão das novas exigências e face a demandas nacionais (EXERCITO BRASILEIRO, 2013). O Objetivo do Proteger é "garantir o funcionamento da infraestrutura e dos serviços essências ao desenvolvimento econômico face às ameaças físicas, além de garantir à proteção da sociedade civil em grandes eventos" (EXERCITO BRASILEIRO, 2013, p.40) A finalidade principal do projeto é a defesa das EETer, estruturas vitais para o funcionamento e manutenção da vida pública - hidroelétricas, gasodutos, redes de abastecimento de água, de telecomunicações, etc. - e a promoção da segurança de grandes eventos, quando o país fica mais vulnerável a, por exemplo, a ações terroristas.

Dada à complexidade do campo em que está inserida tal política pública, a tarefa de se pensar estrategicamente pode se tornar ainda mais difícil. Isso acontece porque um campo de atuação com múltiplos vetores de ameaças e com tantos órgãos com poder sobre a agenda naturalmente dificulta o gerenciamento das ações para tratar os problemas a que se propõe resolver. Analisando os objetivos específicos do projeto percebemos que suas atividades podem ser alocadas em dois eixos, um operacional, e ou outro de inteligência. No e eixo prático estão alocadas os esforços para criação de mecanismos que possam de pronto-imediato responder as ameaças, tais como o treinamento de tropas para assistência em eventos e em casos de ameaças a serviços essenciais. Já o eixo de inteligência é aquele no qual a cadeia de órgãos mantém-se ligada de tal forma que possa desenvolver capacidades de prevenção a qualquer tipo de incidente, e assim diminuir os riscos. 
Artigo original

Hegemonia - Revista Eletrônica de Relações Internacionais do Centro Universitário Unieuro

ISSN: $1809-1261$

UNIEURO, Brasília, número 14, 2014, pp. 88-106.

4. O Sistema Integrado de Monitoramento das Fronteiras Terrestres (SISFRON)

Na América do Sul, os países gozam de certa estabilidade e de um baixo grau de conflitos armado, porém tal condição não isenta outros tipos de ameaça na região. Mesmo não havendo guerra, diversos problemas de segurança se constituem ao longo de suas fronteiras e prejudicam a qualidade da relação entre os estados vizinhos e os indicies de violência dentro dos próprios países. (GARCIA, 2013). O Estado brasileiro conta com uma extensa área fronteiriça onde se interliga com dez países sulamericanos, com os quais têm cultivado relações pacíficas e harmônicas, baseadas fundamentalmente na manutenção da ordem e da paz continental. Mesmo não tendo ocorrido outro conflito de grande proporção na região desde a Guerra do Paraguai (1864-1870), há um esforço contínuo para que seja mantida a unidade do continente e o combate a criminalidade internacional. A proteção das fronteiras então se tornou um ponto importantíssimo na agenda dos países, inclusive do Brasil, onde o escopo fundamental é conter as vulnerabilidades existentes nestas regiões e impedir os avanços do crime transnacional, especificamente do narcotráfico, do tráfico de armas, do contrabando e da imigração ilegal.

O Sistema Integrado de Monitoramento das Fronteiras Terrestres (SISFRON) é um sistema de vigilância e monitoramento que vislumbra dotar a Força Terrestre de meios que garantam uma presença efetiva do Estado em áreas chaves no território nacional, mais especificamente na faixa de fronteira, envolto num Sistema de Comando e Controle e Apoio à Decisão. 
Artigo original

Hegemonia - Revista Eletrônica de Relações Internacionais do Centro Universitário Unieuro

ISSN: $1809-1261$

UNIEURO, Brasília, número 14, 2014, pp. 88-106.

O SISFRON propõe o adensamento das Unidades das Forças Armadas na fronteira, buscando aumentar o número do efetivo ali presente, bem como construir novas bases e recuperar estruturas já existentes. Para o Exército, o SISFRON conseguirá além de incrementar a capacidade de monitoramento da fronteira, garantir um fluxo contínuo e seguro de dados entre distintos escalões da Força Terrestre, sendo possível então a produção de informações confiáveis e oportunas para a tomada de decisões, e no mesmo sentido assegurar uma pronta atuação em ações de defesa ou contra crimes transfronteiriços e ambientais, de acordo com a legislação vigente. (EXÉRCITO BRASILEIRO, 2014)

Segundo informações do Exército Brasileiro (2014), por meio do Escritório de Projetos, o SISFRON compreende um conjunto abrangente e integrado de recursos tecnológicos, estruturas organizacionais, pessoas e processos, constituindo sistemas, cujos principais componentes são: o Subsistema de Sensoriamento, Subsistema de Apoio à Decisão, Subsistema de Tecnologia da Informação e Comunicações e o Subsistema de Simulação e Capacitação. O Subsistema de Sensoriamento tem com escopo fundamental o apoio as ações de vigilância, reconhecimento e monitoramento da área que compõe a faixa de fronteira brasileira, obtendo os dados necessários ao pleno funcionamento do Subsistema de Apoio à Decisão. Sua instrumentalização dar-seá através da utilização de radares de vigilância terrestre e aérea de baixa altitude, de sensores óticos, optrônicos e de sinais eletromagnéticos, espalhados por diversos escalões, a partir de pontos de controle. Na figura 2 abaixo é possível perceber a disposição dos artefatos e área de cobertura proposta no projeto, bem como sua interligação com os centros de controle. 
Artigo original

Hegemonia - Revista Eletrônica de Relações Internacionais do Centro Universitário Unieuro

ISSN: $1809-1261$

UNIEURO, Brasília, número 14, 2014, pp. 88-106.

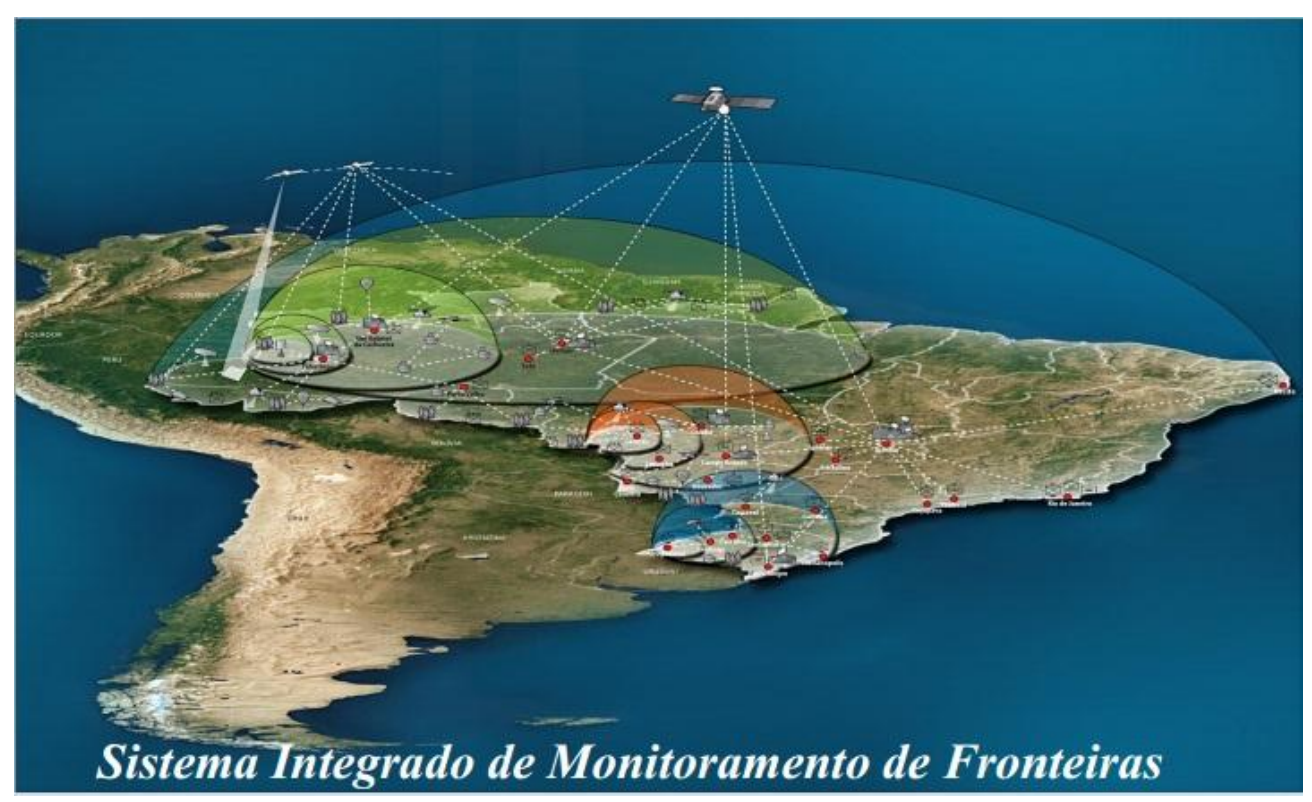

Figura 5 - Fonte: BRASIL. Ministério da Defesa, 2013.

Segundo o Exército Brasileiro (2014), no Subsistema de Tecnologia da Informação e Comunicações é aonde se realiza "o tráfego de dados entre os componentes do SISFRON, possibilitando a integração do sistema e disseminação de serviços e produtos". Tal subsistema é composto ainda de redes de comunicações fixas e móveis, incrementando o aparato disponível. Destaca-se ainda a relação com a Defesa Cibernética, onde é possível garantir a validade dos dados coletados pelo sistema.

Por fim, tem-se o Subsistema de Atuadores que é composto pelas forças militares, pelos órgãos e agências, bem como os produtos de defesa e segurança e os 
Artigo original

Hegemonia - Revista Eletrônica de Relações Internacionais do Centro Universitário Unieuro

ISSN: $1809-1261$

UNIEURO, Brasília, número 14, 2014, pp. 88-106.

procedimentos operacionais utilizados nas missões constitucionais e legais do Exército na fronteira. (EXÉRCITO BRASILEIRO, 2014). Este derradeiro subsistema que compõe o SISFRON é onde encontramos o caráter interagência debatido neste artigo. Embora o desenvolvimento e a implementação do projeto esteja sob a responsabilidade do Exército Brasileiro, especialmente do Setor Cibernético, há o elemento fundamental que é a materialização de uma cooperação institucional entre distintas agências a fim da melhor utilização dos dados coletados. E partindo do pressuposto de que a cooperação interagência no âmbito de SISFRON dar-se maneira institucionalizada é possível notar um esforço geral, envolvendo o trabalho de diferentes instituições, com o objetivo fundamental a contenção das vulnerabilidades na região transfronteiriça brasileira. Bem como aproveitar os dados coletados da melhor forma possível dentro do contexto das missões ali desenvolvidas.

\section{Ações Concretas}

Nessa última parte do texto ficará evidente como os dois eixos de atuação do Proteger, o operacional e o estratégico se complementam e fornecem uma ação especifica concreta para atingir o problema, e como a criação de estruturas básicas possibilitam o desenvolvimento e aprimoramento do SISFRON.

No que tange ao Proteger, tem-se que em 2011 foi criada a Secretaria Extraordinária de Segurança para Grandes Eventos (SESGE), vinculada ao ministério da Justiça, para gerenciar as ações de segurança nos grandes eventos realizados no Brasil. Nas ações da secretaria podemos perceber a confluência desses dois eixos de atuação do Proteger. A SESGE teve o desafio de diagnosticar as deficiências e melhorar as 
Artigo original

Hegemonia - Revista Eletrônica de Relações Internacionais do Centro Universitário Unieuro

ISSN: $1809-1261$

UNIEURO, Brasília, número 14, 2014, pp. 88-106.

estratégias de proteção para cada cidade sede da Copa das Confederações da FIFA realizada em 2013 e para a Copa do Mundo da FIFA de 2014. Percebemos que por meio da coordenação interagência de órgãos de segurança dos estados, dos órgãos das prefeituras locais, de instâncias governamentais ligadas ao Executivo, da Policia Federal, da Policia Rodoviária Federal, do Exército Brasileiro, e vários outros órgãos, a criação dos meios para que os Centros Integrados de Comando e Controle ${ }^{3}$ (CICCs) de cada cidade pudessem funcionar.

O escopo de atuação da SESGE foi o de gerenciar o trabalho entre as diversas agências, para que esses centros de vigilância se concretizassem. E os próprios CICCs denotam o caráter da ação interagência que o monitoramento das cidades-sedes nos períodos dos jogos da Copa do Mundo vai oferecer, já que os próprios CICCs são compostos por diversas instâncias governamentais.

Quando voltamos nosso olhar para a dinâmica da cooperação interagência (ver figura 1) onde podemos perceber as fases desse processo, vemos como a SESGE consegue passar por todas essas fases e chegar a um output concreto, prático - os CICCs - que respondem diretamente ao problema inicialmente identificado.

No que se refere às ações práticas resultantes do projeto SISFRON destacam-se a instalação de novas estruturas organizacionais que acomodem as diferentes agências envolvidas no funcionamento do sistema, bem como a criação de estruturas físicas que levem ao aproveitamento dos dados coletados. A primeira ação concreta implementada

3

Para mais informações sobre os Centros Integrados de Comando e Controle (CICC) visitar página virtual da Secretaria Extraordinária de Segurança para Grandes Eventos (SESGE): < http://sesge.mj.gov.br/> . 
Artigo original

Hegemonia - Revista Eletrônica de Relações Internacionais do Centro Universitário Unieuro

ISSN: $1809-1261$

UNIEURO, Brasília, número 14, 2014, pp. 88-106.

foi à criação do Centro de Monitoramento de Fronteira, na cidade de Brasília, com o objetivo de gerir o SISFRON, realizando ações relacionadas a operações, logística integrada, capacitação de capital humano, simulações, entre outros. Um outro desdobramento fundamenta é a criação dos Centros Regionais de Monitoramento com intenção de fornecer suporte a nível regional para os comandos que tiverem atuação correlata às atividades do SISFRON.

O processo de implantação do SISFRON iniciou-se no ano de 2010 com a contratação da empresa responsável pelo processo de feitura do projeto básico. No ano de 2013 foi possível visualizar as primeiras iniciativas do processo a partir de alguns pontos focais. Destaca-se a implantação do $9^{\circ}$ B ComGE na cidade de Campo Grande MS, bem como a reestruturação do destacamento de Caracol do $10^{\circ} \mathrm{RCMec}$ e a construção do Centro de Operações do CMO. Iniciaram-se também os estudos, projetos e obra do Centro Regional de Monitoramento. Comprou-se ainda optrônicos, rádios e meios de apoio aos atuadores possibilitando uma melhora nos padrões de coordenação e controle, assim como uma maior mobilidade das tropas na faixa transfronteiriça. (EXÉRCITO BRASILEIRO, 2014)

Nesse contexto, é possível então perceber a importância da implementação de ambos os projetos, especialmente, pela necessidade de uma proteção efetiva advinda do setor de defesa nacional para os grandes eventos vindouros. A relação entre os dois projetos é de complementaridade haja vista a relevância dos objetos de proteção centrais, quais sejam: as estruturas estratégicas e a área de fronteira. 
Artigo original

Hegemonia - Revista Eletrônica de Relações Internacionais do Centro Universitário Unieuro

ISSN: $1809-1261$

UNIEURO, Brasília, número 14, 2014, pp. 88-106.

\section{Considerações Finais}

As considerações finais deste paper coadunam-se no sentido de destacar mais uma vez a importância da opção pela cooperação interagência feita pela o Estado brasileiro para atuação na área de defesa. As abordagens tradicionais não mais respondiam aos desafios impostos pela atualidade, e fez com que se buscasse a construção de políticas públicas de defesa coordenadas, valorizando a integração institucional entre distintos atores a fim de alcançar objetivos comuns.

O projeto Proteger emerge enquanto política pública importante para a defesa e proteção de Estruturas Estratégicas Terrestres do Brasil, cuja ausência por qualquer motivo pode trazer grave impacto estrutural, especialmente, de cunho político, econômico e ambiental. Enquanto que o SISFRON coaduna-se como uma política de proteção complementar, onde se tem a questão do enfrentamento de problemas fronteiriços, seja aqueles voltados às questões de defesa nacional, bem como os relacionados à diminuição das vulnerabilidades na região e a incidência de crimes transnacionais, como narcotráfico, contrabando e outros.

Neste sentido, os dois projetos ora debatidos mostram-se de extrema relevância para o país tanto no que se refere à chegada dos grandes eventos, como a melhora do monitoramento da sua "porta de entrada" que é a faixa fronteiriça. Admitindo ainda que grande parte das mazelas sociais está relacionada à violência nas grandes cidades, e que estas se ligam aos eventos ilícitos ocorridos na fronteira, um monitoramento mais eficaz pode ajudar na diminuição desse efeito reflexo para todo país. Da mesma forma, 
Artigo original

Hegemonia - Revista Eletrônica de Relações Internacionais do Centro Universitário Unieuro

ISSN: $1809-1261$

UNIEURO, Brasília, número 14, 2014, pp. 88-106.

ao garantir a segurança de estruturas fundamentais, o projeto Proteger reitera a necessidade de políticas contínuas para a proteção de áreas estratégicas brasileiras.

Referências e Bibliografia

BRASIL. Ministério da Defesa. Sisfron: o projeto estratégico do Exército Brasileiro. Julho, 2013. Disponível em: <http://www.defesa.gov.br/projetosweb/cedn/arquivos/palestras-junho-2013/osisfron-projeto-estrategico-do-exercito.pdf> Acesso em 10 de abril de 2014. . Manual de Operações em Ambiente Interagência. 1 edição. 2013.

EXERCITO BRASILEIRO. Projetos Estratégicos do Exército Brasileiro. Military Review. Jan/Fev. 2013.

- Escritório de Projetos do Exército Brasileiro. Sisfron. Disponível em: <http://www.epex.eb.mil.br/index/sisfron/cont_01.php>. Acesso em 10 de abril. 2014.

GARCIA, Stephanie Q. A Política de Defesa do Brasil para as Áreas de Fronteira: interação entre governo e agências. Anais do $4^{\circ}$ Encontro da Associação Brasileira de Relações Internacionais. Belo Horizonte. 2013.

RAZA, Salvador. Cooperação Interagências: Porque e como funciona um estudo de modelos organizacionais nas Relações Internacionais? Brazilian Journal of International Relations, São Paulo, v. 1, n.1, p. 7-37, 2012. 


\section{Artigo original}

Hegemonia - Revista Eletrônica de Relações Internacionais do Centro Universitário Unieuro

ISSN: $1809-1261$

UNIEURO, Brasília, número 14, 2014, pp. 88-106.

WARMINGTON, P. et.al. Interagency Collaboration: a review of the literature. Disponível em:<http://www.bath.ac.uk/research/liw/resources/Microsoft\%20Word\%2

0\%20Interagency_collaboration_a_review_of_the_literature_initial.pdf $>$. Acesso em 20 de junho 2013. 